\title{
A Quick-Response Discrete Transit-Share Model for Transit-Oriented Developments
}

\author{
Mohan Venigalla, Ph.D., P.E. \\ George Mason University \\ Arsalan Faghri, Ph.D., P.E. \\ Virginia Department of Transportation
}

\begin{abstract}
Various studies have highlighted an apparent lack of analyses associated with the modal choice characteristics of transit-oriented developments (TODs) and emphasized the need for quick response models for estimating transit share in TOD areas. In this paper, a methodology for developing transit-share model for TOD's using travel activity data is presented. A transit-share model is formulated as an innovative combination of the direct generation, urban travel factor (UTF), and logit models. This model determines transit usage in TODs based on household auto ownership as the primary input and the transit system variables as secondary inputs. Validation of the model indicates a close agreement with observed data. Since the input requirements to the TOD transit-share model are minimal, this model structure is expected to be very useful for sketch analysis of many TOD project alternatives.
\end{abstract}

Keywords: Transit-oriented development, TOD, mode choice models, livability in transportation, smart growth.

\section{Introduction}

The concept of "smart growth" has been recognized as a robust urban planning alternative to the status quo of urban sprawl. Transit-oriented developments (TODs), as a form of land use, attempt to reduce auto trips by promoting the use of public transit and developing high-density mixed land uses (TCRP 2004; CTOD 2010). Thus, TODs are fundamental for a successful smart-growth policy.

The rapid pace in developing TODs and the relative neglect of this land-use phenomenon in the past has left policymakers and transportation planners in the United States with inadequate knowledge related to trip characteristics of TODs. The 
travel demand parameters necessary to predict trip generation activity, develop trip distribution models, identify mode choice characteristics, and determine assignment of TOD-based trips are yet to be fully explored.

The state of the practice in transportation planning includes mode choice model development and application at a resolution where traffic analysis zones (TAZs) are aggregated to the district level (Milone 2013). Such aggregation to the district level loses the fidelity associated with the unique nature of TODs. Despite significant influence of TODs on mode choice, few studies have attempted to develop disaggregated mode choice models to be used in conjunction with TAZs containing TODs. Cervero (2002) ascertained that neither trip generation nor mode choice models included density or any other land-use variables. Time constraints and data limitations precluded the recalibration of models to directly account for built-environment influences. Disaggregate models have potential for use in various sketch planning tools, which are commonly employed during the preliminary planning stages of TODs.

Various studies have indicated an apparent lack of analyses associated with the modal choice characteristics of TOD areas. There is limited data and analysis to ascertain the net shift in travel modes of TOD residents before and after relocating to a TOD environment (Hendricks et. al. 2005). The 2003 California TOD travel characteristics study and the 2005 surveys of Portland-area TODs and transit-adjacent developments for the TransNow Center attempted to determine the net mode shift in TOD residents before and after relocating to a TOD environment. Results of these studies ranged from $2-16 \%$ gain in transit mode share after relocation (TCRP 2007). The gain in transit mode share included a significant change to the workplace by the TOD residents. The correlation between transit mode share and the proximity of workplace to a transit station is equally important to mode shift in a TOD environment than the place of residence alone (Cervero 1993).

A number of studies have identified one-quarter mile radius (approximately 1,300 ft) around a mass transit station as the ideal walking distance for a successful patronage of transit among TODs (Ashalalfah and Shalaby 2007; Lund 2006; Lund et al. 2010). O'Sullivan and Morall (1996) indicated that the average walking distance to suburban stations in the city of Calgary was 649 meters ( 0.40 miles), with a $75^{\text {th }}$ percentile of 840 meters ( 0.52 miles); however, the average and the $75^{\text {th }}$ percentile walking distance at CBD stations were 326 meters ( 0.20 miles) and 419 meters ( 0.26 miles), respectively (O'Sullivan 1996). On the same note, Cervero (1993) determined that the number of residents in the Bay Area who moved to 0.5 -mile radius of a transit station and switched their mode of travel from personal passenger car to transit exceeded $50 \%$.

A few mode choice studies of TOD residents and office workers typically show that transit travel times and their comparison to private car travel times is the strongest predictor of transit ridership. In other words, travel time differentials are a critical factor, and these differentials can vary greatly depending on local circumstances (Arrington and Cervero 2006). In a study on transit usage by residents of TODs by various trip purposes, Chatman (2006) randomly selected households and workers within 0.4mile radius of transit stations in San Diego and San Francisco, California, and collected 
24-hour activity and trip diary via phone survey. The study concluded that people living or working near Metrorail stations have a higher non-auto share of commuting and non-work travel. The study further determined that the non-auto share dissipates as the proximity to transit stations increases.

TOD impacts are measured by studying mode choice variations before and after relocating to a TOD environment and also by comparing mode choice in TOD environments with non-TOD environments. Results of an analysis of data associated with the greater Washington DC area show that work, shop, and entertainment trips in TOD areas were performed mainly via transit (Faghri and Venigalla 2013; Faghri 2012).

Messenger and Ewing (1996) observed that bus mode share by place of residence proved to be dependent primarily on automobile ownership and secondarily on jobs-housing balance and bus service frequency. Automobile ownership, in turn, proved to be dependent on household income, overall density, and transit access to downtown. Thus, three types of variables-socio-demographic, land use, and transit service-were found to affect bus use through a web of interrelationships.

Gebeyehu and Shin-ei (2007) found that bus fare, convenience, and frequency have a significant effect on user satisfaction with bus services. Using a binary logit model, Lin and Jen (2009) found that household income, household size, and floor space needs are negatively associated with TODs and the presence of children or older adult family members and preference for mixed land use are positively associated with TODs. The results of the study indicated that the household size has a negative impact on the decision to live in a TOD community. Furthermore, having children or older adult family members was positively associated with the preference to live in a TOD area.

Cervero (2002) argued for the explicit inclusion of land-use variables in the utility expressions of mode choice models in urbanized settings. Recalibrating mode choice models to incorporate characteristics of built environments is no easy task, in part because in many metropolitan areas variables related to land-use diversity and urban design are not readily available. Additionally, TODs are usually much smaller in size than the smallest geographic aggregation units, also known as traffic analysis zones or TAZs, in the traditional travel demand modeling methods such as the four-step planning process. For this reason, TOD data are aggregated to the level of its TAZ, thereby losing the fidelity of the TOD influence on trip-making and travel behavior. An alternative approach to incorporating land-use factors in the mode choice models is to treat certain TODs as separate TAZs and develop TOD specific disaggregate models for travel-demand forecasts.

This research seeks to address the gap in methodologies for developing and validating disaggregate transit choice model for work trips associated with TOD. The travel activity data from the 2007/2008 household travel survey within the Washington DC metro area are used for model development and validation. The logit model estimates TOD transit-share with household auto ownership as the primary predictor and transit variables as the secondary predictor. The attributes that represent the attractiveness (or the cost) associated with transit mode in the greater metro Washington DC area 
include transit travel time ( $\mathrm{min}$ ), average wait time ( $\mathrm{min})$, transit fare cost (dollars), and average walk time to a transit station (min).

\section{Model Framework}

A common framework for the choice process is that an individual first determines the available alternatives, then evaluates the attributes of each alternative relevant to the choice under consideration, and finally uses a decision rule to select an alternative from among the available alternatives (Ben-Akiva and Lerman 1985). The attractiveness of an alternative is determined by the relative values of the utilities of all alternatives in the set (Lancaster 1971). Utility is an indicator of value to an individual. The utility maximization rule states that an individual will select the alternative from his/her set of available alternatives that maximizes his/her utility (Koppelman and Bhat 2006).

The utility $U$ of a mode $i$ (designated as $U_{i}$ ) is composed of a set of attributes (independent variables), which describes the attractiveness of a mode. A typical utility function frequently used in mode choice modeling assumes a linear form shown in Equation 1.

$$
U_{i}=a_{i}+b_{i} \times T T_{i}+c_{i} \times W T_{i}+d_{i} \times \operatorname{COST}_{i}+e_{i} \times W K T_{i}
$$

Where,

$$
\begin{aligned}
& U_{i}=\text { Utility of mode } i \\
& T T_{i}=\text { transit travel time for mode } i \\
& W T_{i}=\text { average wait time for mode } i \\
& C O S T_{i}=\text { cost of mode } i \\
& W K T_{i}=\text { average walk time for mode } i \\
& a_{i}=\text { model constant } \\
& b_{i}, c_{i}, d_{i} \text {, and } e_{i}=\text { coefficients for each attribute for mode } i
\end{aligned}
$$

Deterministic choice models are based on the utility maximization rule. Whereas the absolute values of utility of a mode are meaningless, the rule states that an individual chooses the alternative with the highest utility, implying no uncertainty in the individual's decision process. The probabilistic choice models describe preferences and choice in terms of probabilities of choosing each mode among a competing set of travel modes (e.g., drive-alone, carpool, transit, walk, and bike) rather than predicting that an individual will choose a particular mode with certainty. Effectively, these probabilities reflect the population probabilities that people with the given set of characteristics and facing the same set of alternatives choose each of the alternatives (Koppelman and Bhat 2006). Probabilistic mode choice models often are formulated as logit models, mainly in the forms of multinomial logit (MNL) and nested logit (NL) (Chatterjee and Venigalla 2003). In the logit model framework, the relative difference in the utility value of competing modes manifests itself into the choice probabilities of the modes. 
Formulating choice probabilities among competing alternatives (e.g., auto, carpool, transit) as logit models has been the traditional norm in mode choice modeling. Input data requirements for logit models can be extensive. A typical mode-share model requires as input transit travel time, average wait time, cost, and average walk time for each mode. Such extensive input requirements make the applicability of the mode choice models fairly restrictive to cases in which adequate input data are available.

On the other hand, sketch planning tools/models, which offer quick turnaround while requiring limited input data, are widely used in the evaluation of transportation projects, especially in the preliminary planning process. There is a dearth of sketch choice models for evaluating transit share in TOD areas. The potential of various other forms of transit mode-split models, such as the direct generation method and the urban travel factor (UTF) model for TOD transit-share estimation, are examined (Figure 1). In the direct generation methods, transit trips are generated directly either by estimating total person trips or by auto driver trips. In the UTF model, transit probabilities are formulated as a function of autos per household and/or population density (Garber and Hoel 2010). The advantage of the direct generation and UTF models is the model simplicity, especially in terms of input requirements.

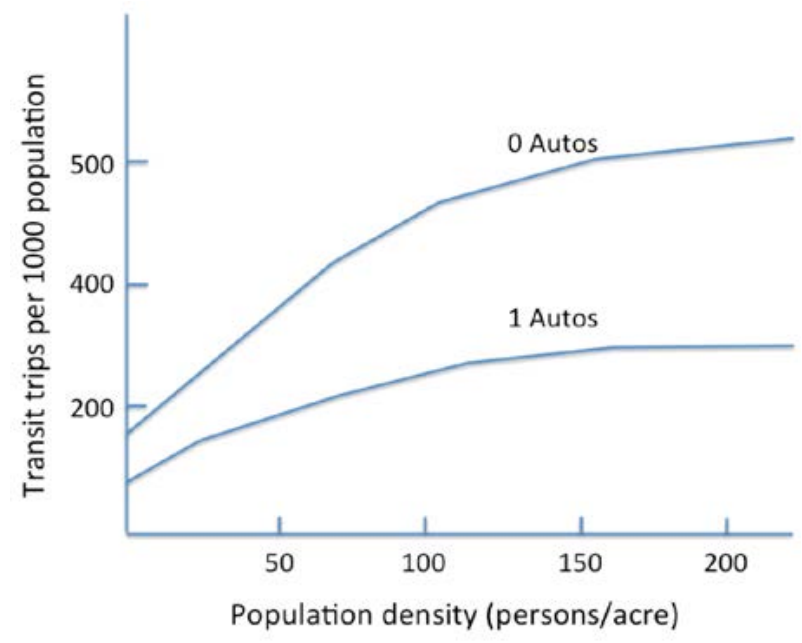

(a) Transit trips vs. auto-ownership and population density

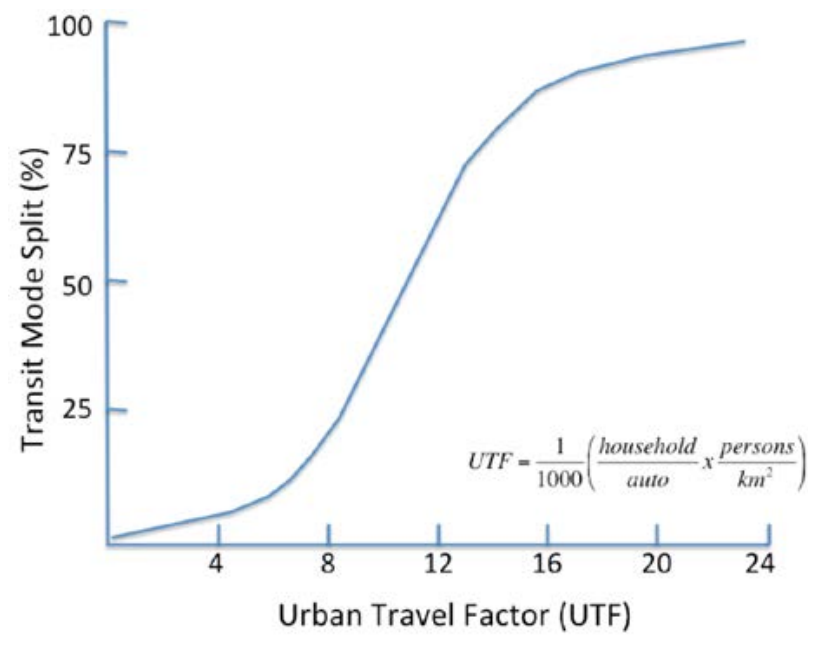

(b) Transit mode split vs. urban travel factor

FIGURE 1. Non-traditional quick response models for estimating transit share (adapted from Garber and Hoel 2010)

An innovative transit-share model is formulated as a combination of the direct generation, UTF, and logit models. This transit share model is aimed at determining transit usage in TODs based on household auto ownership as the primary input and only the transit variables (travel time, average wait time, and average walk time) as secondary inputs. The transit-share probabilities for a given auto are obtained from the MNL formulation shown in Equation 2. 


$$
P_{t i}=\frac{e^{U_{i}}}{\sum_{i=1}^{k} e^{U_{i}}}
$$

Where,

$P_{t i}=$ Probability of transit as the primary mode choice of work trips for auto ownership, $i$ ( $i=0,1,2$, and 3 )

$U_{i}=$ Transit utility value for auto ownership, $i$

The associated set of stochastic transit utility models $\left(U_{i}\right)$ for a given auto ownership (i) are developed using multinomial logistic regression. The utility models represent utility of auto mode for a given set of transit variables. The independent transit variables associated with utility function $U_{i}$ of the TOD transit-share model in the greater Washington DC area are assumed as transit travel time ( $\mathrm{min}$ ), average wait time (min), transit fare cost (dollars), and average walk time to a transit station (min).

\section{Case Study}

The data used for this research are from the 2007/2008 household travel survey obtained from the National Capital Region Transportation Planning Board (TPB) of the Metropolitan Washington Council of Governments (MWCOG). The activity-based survey data provide a wealth of transit-oriented corridors and diverse land uses. The use of these data mitigates loss of computational information frequently ensued by aggregate data, hence providing a more accurate quantitative forecast. The data include a survey of 24-hour activity-based travel patterns for 11,000 households in the greater Washington DC area, which includes northern Virginia and parts of Maryland. The survey contains more than 25,000 person records, 16,000 vehicle records, and 130,000 trip records (MWCOG 2010). A disaggregate mode choice model is a suitable modeling selection for this study, due to disaggregate nature of the data.

\section{Data Preparation}

The data refinement process is a series of data manipulation and extraction via the use of MS Access and Arc GIS. The trip file from the MWCOG trip diary survey data is used to extract trips associated with the Rosslyn-Ballston corridor. The TAZs that were associated with the Rosslyn-Ballston corridor were identified and filtered through the trip file to obtain the number of trips inside the corridor. Home-based work trips that use transit as the primary mode of travel were extracted from the 24-hour activity based data. The data were screened further to include only transit trips from the travel survey data that are within the 0.25 -mile radius of all transit stations to include in the development of the TOD transit-share model. More details about data preparation are discussed in the dissertation work done by Faghri (2012).

The Rosslyn-Ballston corridor in Arlington, Virginia, which is arguably the showcase of a transit-oriented corridor in the nation, was selected as the TOD set for the case study (Figure 2). Each of the five TODs is represented by 0.25 -mile radius around the Ballston, Virginia Square-GMU, Clarendon, Court House, and Rosslyn Metro stations. The reliable high-speed Metro transit service coupled with the interconnecting bus transit system provides a wellconnected network of public transit for a variety of trip purposes in this corridor. 
FIGURE 2.

TOD areas selected for model development

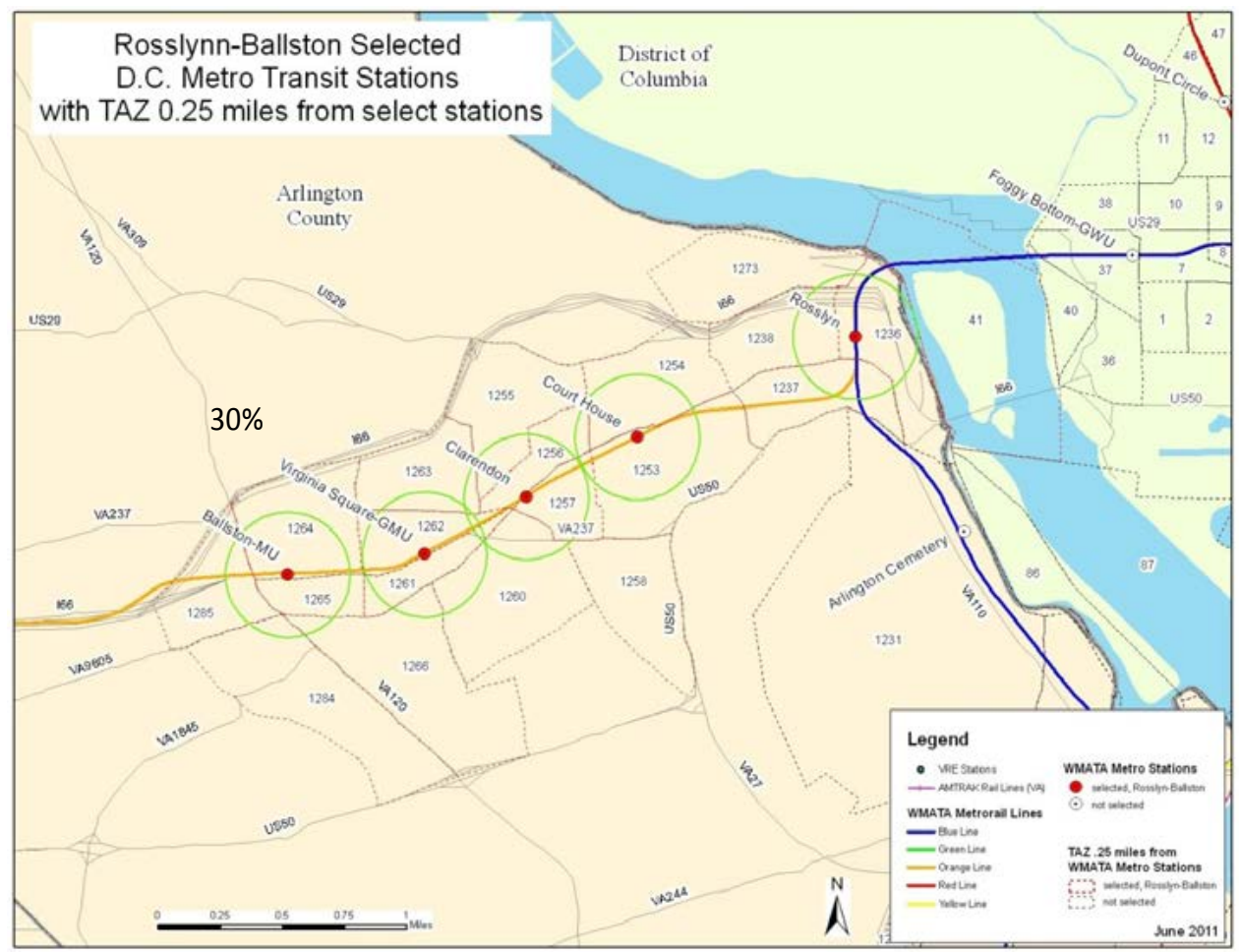

The TOD trips include trips within the TOD zone, as well as to and from non-TOD zones. Similarly, non-TOD trips include all trips within non-TOD areas as well as trips to and from TOD areas. The rate of use of transit within TOD zones is observed to be $12.5 \%$, which far exceeds the $3 \%$ transit usage in non-TOD zones. Conversely, the rate of use of personal vehicles in non-TOD zones is higher than trips to, from, and between TOD zones.

As would be expected, the rate of use of transit within TOD zones far exceeds non-TOD zones (Figure 3). Similarly, the rate of use of personal vehicles in non-TOD zones is higher than trips to, from, and between TOD zones. However, a surprising element in the data is that when the rate of use of personal vehicles is compared inside vs. outside TOD zones, one can observe a higher rate for personal vehicle as opposed to transit usage. Figure 4 illustrates primary travel mode of work trips within TOD and non-TOD zones. As the figure illustrates, the share of trips by transit, walk, and bike modes are much larger in the TOD zone. At the same time, the non-TOD zones show larger share of auto mode. 
FIGURE 3.

Primary travel model of work trips: TOD vs. non-TOD

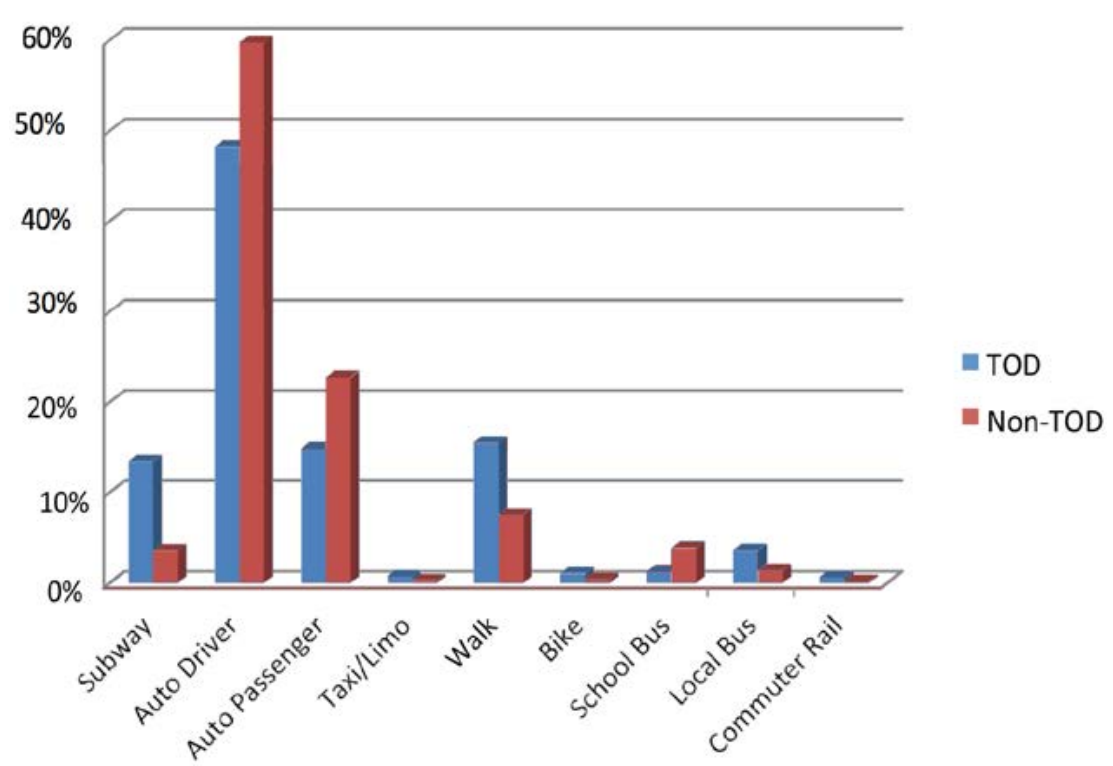

FIGURE 4.

Primary travel model of work trips: TOD vs. non-TOD

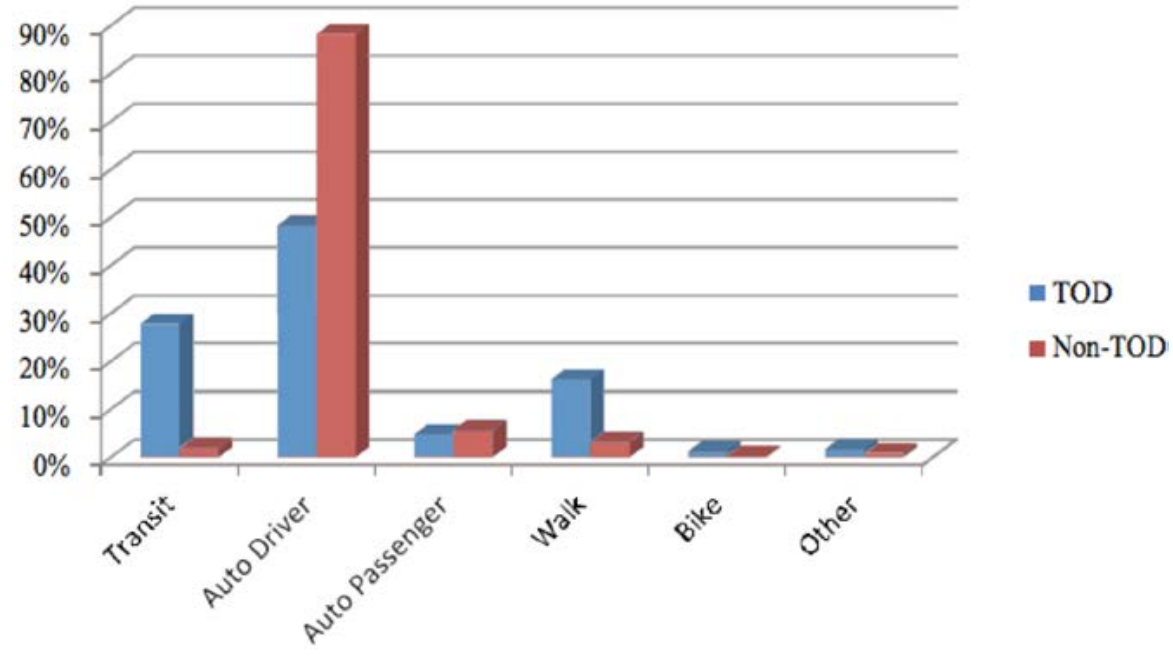

\section{Metrorail Fare Model}

The travel activity data lacked information on transit fare and average wait time. The survey data were augmented by generating required independent variables using the models developed or borrowed for estimating transit fare (Metrorail fare) and average wait times. The Metrorail fare data were obtained from the WMATA website, which contains extensive fare tables from every transit station to all other locations. A regression equation was developed to determine the regular Metrorail fare based on miles traveled and the travel time. A random set of 169 data points was selected; the data points pertain to traveling from a station to all other stations. The independent variables are travel time ( $\mathrm{min}$ ) and distance (miles) between the two stations. The regression model, thus, developed is shown in Equation 3: 


$$
Y=2.0196+0.00167 X_{1}+0.0210 X_{2}
$$

Where:

$Y$ is the Metrorail fare in dollars (\$)

$X_{I}$ is miles travelling distance between the two stations, and

$X_{2}$ is travel time in seconds

The regression coefficient $\left(\mathrm{R}^{2}\right)$ of the transit fare model is 0.88 , the probability of Type I error of the model is nearly zero, and the standard error is 0.30 . These regression parameters indicate that Equation 3 represent a robust transit fare model. The model was used as the basis to determine the Metrorail fare cost between the transit trip stations.

\section{Average Transit Wait Time}

For a long time, the average transit wait time is simply half the headway time between train arrivals. This model is based on random arrival of passengers and uniform arrival of trains, while passengers get on the first train that arrives (Holroyd and Scraggs 1966).

This model is widely accepted until the assumption of uniform and on-time arrival of trains is questioned. If train arrival is non-uniform, then the average waiting time for the passenger is expected to be longer. Osuna and Newell (1972) conducted research to overcome the shortcomings of the traditional model and developed a model for the expected waiting time $W$, which is a function of the average headway $\mu$ and variations in the headway $\mathrm{s}^{2}$ (Equation 4):

$$
W=\mu *\left(1+\frac{s^{2}}{\mu^{2}}\right) / 2
$$

Where:

$$
\begin{aligned}
& W=\text { expected passenger waiting times, } \\
& \mu=\text { mean headways between buses, } \\
& s^{2}=\text { variances of headways between buses }
\end{aligned}
$$

This equation was used to determine the expected wait times in the development of the transit utility model for this section. Transit fare and average transit wait times were then computed for each record in the travel survey data. Table 1 illustrates the input data set, which comprises data elements from the travel surveys as well as the transit attributes computed for inclusion in the transit share model. 
TABLE 1.

Sample Input Data for Transit

Share Model

\begin{tabular}{|c|c|c|c|c|c|c|c|c|}
\hline \multicolumn{9}{|c|}{$\begin{array}{c}\text { Work Trips in 0.25-mile radius TAZs } \\
\text { Purpose=2 (Work) }\end{array}$} \\
\hline Purpose & $\begin{array}{c}\text { Sample } \\
\text { No. }\end{array}$ & Trip ID & Autos & $\begin{array}{c}\text { Income } \\
(\$ 10,000)\end{array}$ & $\begin{array}{c}01= \\
\text { Transit } \\
\text { Travel } \\
\text { Time }\end{array}$ & $\begin{array}{c}\text { Avg. Wait } \\
\text { Time for } \\
\text { Train } \\
(\text { min) }\end{array}$ & $\begin{array}{c}\text { Fare Cost } \\
\text { (based on } \\
\text { Travel } \\
\text { Time })\end{array}$ & $\begin{array}{c}\text { Average } \\
\text { Walk Time } \\
\text { to Transit } \\
(\mathrm{min})\end{array}$ \\
\hline 2 & 2100009 & 21000090203 & 2 & 9 & 60 & 3.97 & 5.45 & 5.34 \\
\hline 2 & 2100027 & 21000270208 & 2 & 10 & 39 & 3.19 & 4.295 & 5.29 \\
\hline 2 & 2100030 & 21000300105 & 4 & 9 & 30 & 2.89 & 3.8 & 0.29 \\
\hline 2 & 2100122 & 21001220109 & 2 & 11 & 57 & 0.16 & 5.285 & 2.08 \\
\hline 2 & 2100141 & 21001410110 & 1 & 8 & 75 & 1.63 & 6.275 & 0.18 \\
\hline 2 & 2100154 & 21001540105 & 2 & 9 & 50 & 0.48 & 4.9 & 1.26 \\
\hline 2 & 2100187 & 21001870111 & 1 & 4 & 57 & 3.91 & 5.285 & 3.35 \\
\hline 2 & 2100295 & 21002950211 & 1 & 9 & 55 & 2.41 & 5.175 & 5.29 \\
\hline 2 & 2100467 & 21004670103 & 2 & 11 & 20 & 0.04 & 3.25 & 0.27 \\
\hline 2 & 2100467 & 21004670105 & 2 & 11 & 68 & 1.82 & 5.89 & 3.39 \\
\hline 2 & 2100626 & 21006260204 & 2 & 9 & 10 & 2.35 & 2.7 & 0.82 \\
\hline
\end{tabular}

\section{Testing for Normality and Variable Transformations}

According to the Central Limit Theorem, 1,660 data points comprise a sufficiently large set to ensure normality of mean for independent variables of the utility models. However, since some of the data pertaining to independent variables are generated using submodels (Metrofare model and wait-time model), a further look at the normality of independent variables was undertaken. The independent variables were subjected to various transformations to ensure normality. Figure 5 illustrates the transformation necessary for the independent variable travel time to maintain a normal distribution. 

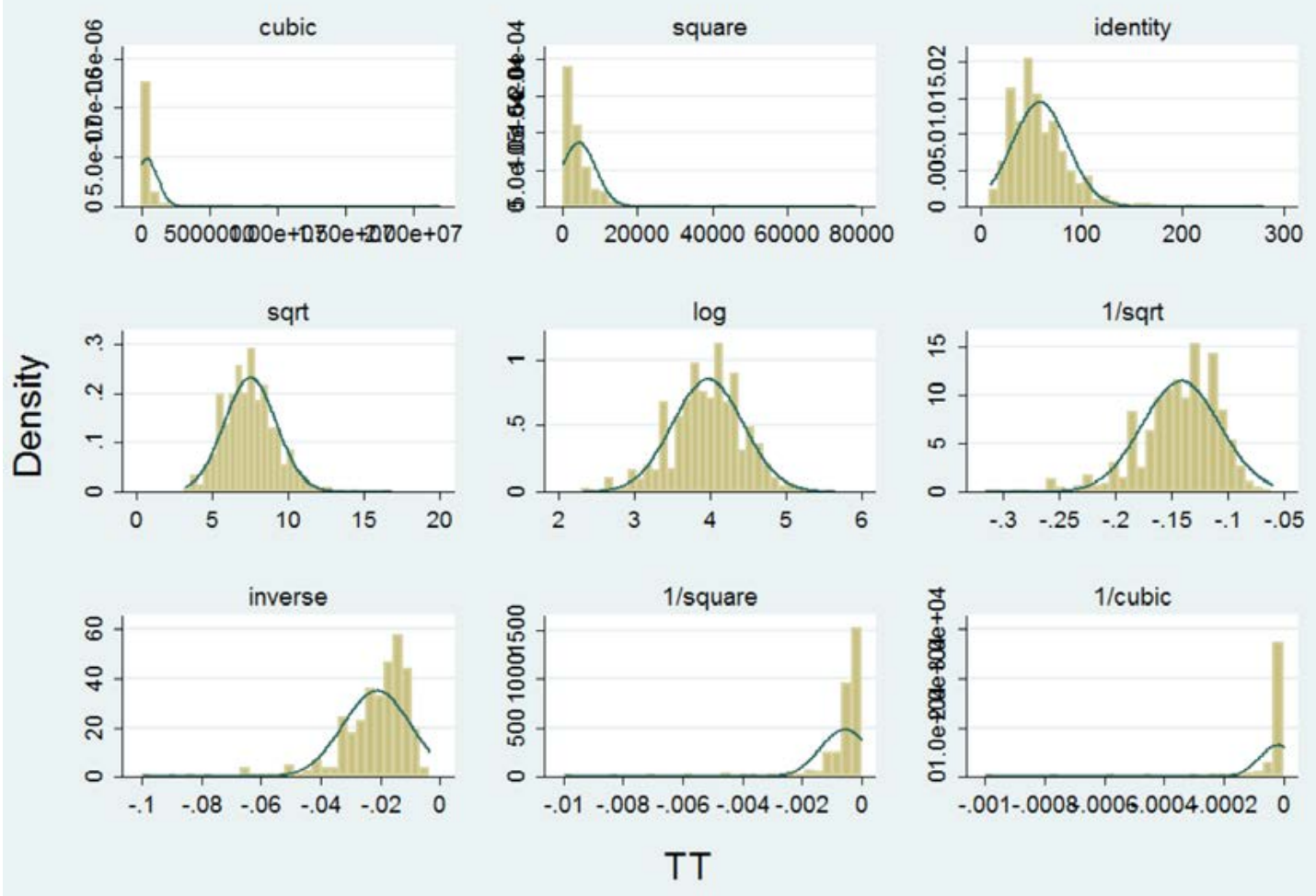

Histograms by transformation

FIGURE 5. Regression Diagnostic Plot - Travel Time Transformation

As the figure indicates, the natural logarithmic transformation of travel time ensures a normal distribution. In this particular case, normality of the predictor variables also was justified by the Kernel density estimate graphs. Variables wait time, cost, and walk time also were tested for normality with similar transformations (not shown in this paper). Table 2 shows the summary of data transformation that is necessary for the predictor variables to maintain normality. 
TABLE 2.

Mode Choice Model-

Predictor Variable Transformation

\begin{tabular}{|c|c|}
\hline Variable & Transformation \\
\hline Travel time & Natural $\log (\ln )$ \\
\hline Wait time & Identity \\
\hline Cost & Inverse \\
\hline Walk time & Identity \\
\hline
\end{tabular}

\section{Model Development}

For households in which transit is the primary mode for work trips, transit utility functions for different levels of household auto ownership were developed using the data analysis and statistical software Stata. The following multinomial logistic regression (MLR) models (Equations 5-8) represent the said utility functions developed for the TOD transit-share model:

$$
\begin{aligned}
& U_{0}=1.16-0.667 * \ln (T T)+0.559 *\left(W_{-} T\right)+14.523 *(\text { Cost })^{-1}-0.0079 *\left(W K_{-} T\right) \\
& U_{1}=7.08-1.408 * \ln (T T)+0.0923 *\left(W_{-} T\right)+4.20 *(\text { Cost })^{-1}-0.401 *\left(W K_{-} T\right) \\
& U_{2}=4.681-0.7424 * \ln (T T)+0.0645 *\left(W_{-} T\right)+0.799 *(\text { Cost })^{-1}-0.1021 *\left(W K_{-} T\right) \\
& U_{3}=5.213-0.8478 * \ln (T T)+0.0530 *\left(W_{-} T\right)-5.230 *(\text { Cost })^{-1}-0.0354 *\left(W W_{-} T\right)
\end{aligned}
$$

Where,

$$
\begin{aligned}
& T T=\text { Trip travel time }(\mathrm{min}) \\
& W_{-} T=\text { Wait time }(\mathrm{min}) \\
& \text { Cost }=\text { Transit Fare Cost }(\$) \\
& W K_{-} T=\text { Walk time to transit station }(\mathrm{min})
\end{aligned}
$$

MLR models use the "maximum likelihood estimation," which is an iterative process to reach minimum log likelihood. When the difference between two successive iterations is small, the model is converged, and no smaller value of log likelihood exists. Table 3 shows the results of above MLR models. The iteration log shows the list of log likelihood at five iterations until the model is converged. 
TABLE 3.

Transit Trips MLR Summary of Results

\begin{tabular}{|c|c|c|c|c|c|}
\hline Vehicle & Variable & Coef & P Value & \multicolumn{2}{|c|}{$\begin{array}{c}95 \% \text { Confidence } \\
\text { Interval }\end{array}$} \\
\hline \multirow{5}{*}{0} & Travel time & -0.6674 & 0.526 & -2.7323 & 1.3975 \\
\hline & Wait time & 0.0559 & 0.655 & -0.1891 & 0.3010 \\
\hline & Fare cost & 14.5238 & 0.159 & -5.6660 & 34.7138 \\
\hline & Walk time & -0.0079 & 0.933 & -0.1936 & 0.1777 \\
\hline & Constant & 1.1607 & 0.851 & -10.9510 & 13.2726 \\
\hline \multirow{5}{*}{1} & Travel time & -1.4085 & 0.150 & -3.3253 & 0.5082 \\
\hline & Wait time & 0.0923 & 0.427 & -0.1356 & 0.3230 \\
\hline & Fare cost & 4.2002 & 0.661 & -14.601 & 23.0014 \\
\hline & Walk time & 0.0401 & 0.649 & -0.1328 & 0.2131 \\
\hline & Constant & 7.0832 & 0.217 & -4.1595 & 18.3261 \\
\hline \multirow{5}{*}{2} & Travel time & -0.7424 & 0.427 & -2.5759 & 1.0911 \\
\hline & Wait time & 0.0645 & 0.581 & -0.1649 & 0.2941 \\
\hline & Fare cost & 0.7990 & 0.931 & -17.3349 & 18.9331 \\
\hline & Walk time & 0.1021 & 0.250 & -0.7192 & 0.2763 \\
\hline & Constant & 4.6814 & 0.394 & -6.0940 & 15.4569 \\
\hline \multirow{5}{*}{3} & Travel time & -0.8478 & 0.456 & -3.0757 & 1.3800 \\
\hline & Wait time & 0.0530 & 0.684 & -0.2026 & 0.3086 \\
\hline & Fare cost & -5.2308 & 0.639 & -27.0793 & 16.6176 \\
\hline & Walk time & 0.0354 & 0.720 & -0.1585 & 0.2294 \\
\hline & Constant & 5.2128 & 0.435 & -7.8616 & 18.2874 \\
\hline$\geq 4$ & \multicolumn{5}{|c|}{ Base outcome } \\
\hline Number of Obs & 1,660 & \multirow{5}{*}{\multicolumn{4}{|c|}{$\begin{array}{l}\text { The Likelihood Ratio (LR) test is represented by LR } \\
\text { chi }^{2} \text { and is an indication if the model is significant. } \\
\text { This value indicates that the likelihood ratio that } \\
\text { for all equations at least one of the predictors' } \\
\text { regression coefficients is not equal to zero. }\end{array}$}} \\
\hline $\operatorname{LR~chi~}^{2}(16)$ & 150.08 & & & & \\
\hline P-value & 0.0000 & & & & \\
\hline Pseudo R ${ }^{2}$ & 0.0336 & & & & \\
\hline Log likelihood & $-2,158.6122$ & & & & \\
\hline
\end{tabular}

- Null hypotheses: regression coefficients across all models are equal to zero.

- When P-value is compared with a pre-set tolerance to accept a Type I error of $\alpha=0.05$, the null hypothesis is rejected.

- The confidence intervals $(\mathrm{Cl})$ shown indicate that for a particular predictor we are $95 \%$ confident that the "true" coefficient lies between the lower and upper limit of the interval. If the $\mathrm{Cl}$ includes zero, we would fail to reject the null hypothesis

\section{Validation}

The model results were tested against the survey data to determine the validity. Using 40 data points, two sets of probability values were determined. The first set was what was obtained through the use of the logit model, and the second set was simply the probability of occurrence of the data points in the data set. This comparison in effect provided the probability of taking transit as the primary mode of travel in a transitoriented environment given the users are classified as having $0,1,2$, and 3 vehicles. 
Figure 6 is an illustration of the results, which indicate that not only the use of transit decreases as the number of vehicles owned increases, it also validates models 13-16 and shows that the probability of using transit is similar between what is derived by the logit model and the observed values.

FIGURE 6.

Average probabilities of transit use as primary mode for work trips: Modeled vs. observed

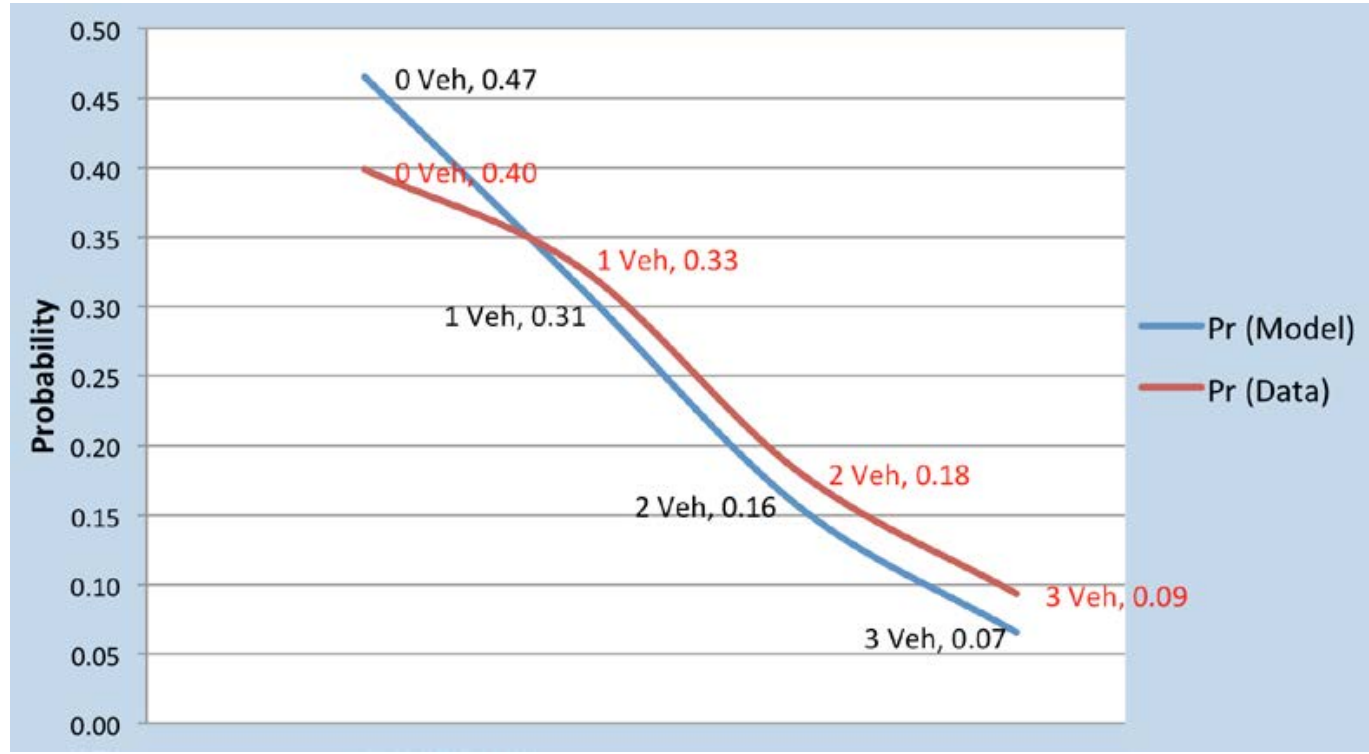

\section{Conclusions and Discussion}

A methodology for developing a disaggregate transit-share model for transit-oriented developments using the travel activity data is presented using Rosslyn-Ballston TOD corridor in the Washington Metro area as the case study. The model offers quick response method for estimating transit share of work trips in TODs. Consistent with intuition, the results indicate that the use of transit decreases as the number of vehicle ownership increase. Validation of the model indicated close agreement with observed data. Since the input requirements to the TOD transit-share model are minimal, this model is expected to be very useful for sketch analysis of many TOD project alternatives, especially in the Washington DC metro area and other comparable areas.

The model is useful as a sketch-planning tool in evaluating various policy alternatives for the existing or new TODs in the same or comparable urban areas. In the preliminary planning stages of a TOD project, by employing this model, planners can quickly estimate transit share of trips in the TOD area by controlling for policy variables such as household auto ownership, transit schedules and fare, walk access to transit stops, etc. Such quick-response modeling will lead to identification of a set of feasible alternatives that can be evaluated later during the detailed planning stage using more robust models.

The methodology presented in this paper is transferable to all TODs surrounding major transit stations and can be replicated in urban areas where location-specific travel activity data are available. Whenever travel survey data with adequate spatial resolution 
are available, it is recommended that separate trip generation and mode choice models be developed for TODs.

Disaggregate trip generation and mode choice models are widely regarded as better models for travel demand modeling applications. However, due to a mismatch between TOD and TAZ in terms of special resolution, the applicability of disaggregate models developed for TODs in traditional travel demand modeling needs further exploration. Since most TODs are usually much smaller than TAZs, in the absence of a structured sensitivity analysis, it is not clear if differentiating trip generation models for TODs and other land uses will automatically lead to better results from the travel demand modeling process. A worthwhile extension of this study will be to treat TODs surrounding major transit stations as separate TAZs and examine the influence of the disaggregate models on overall travel demand model results.

\section{Acknowledgments}

The authors would like to thank the Virginia Department of Transportation (VDOT) and Metropolitan Washington Council of Governments (MWCOG) for sharing the data for this research. The contribution of William Sitterle at VDOT is gratefully acknowledged.

\section{References}

Alshalalfah, B., and A. Shalaby. 2007. "Case Study: The Relationship between Walk Access Distance to Transit with Service, Travel, and Personal Characteristics." Journal of Urban Planning and Development, 133(2): 114-118. DOI 10.1061/ (ASCE). 07339488(2007).

Arrington, G. B., and R. Cervero. 2006. "Effects of TOD on Housing, Parking, and Travel." TCRP Report 128, Washington, DC: Transportation Research Board.

Ben-Akiva, M., and S. R. Lerman. 1985. Discrete Choice Analysis: Theory and Application to Travel Demand. MIT Press.

Center for Transit Oriented Development (CTOD). 2010. "Transit Corridors and TOD Connecting the Dots."

Cervero, R. 1993. "Ridership Impacts of Transit-Focused Development in California." University of California at Berkeley Institute of Urban and Regional Development.

Cervero, R. 2002. "Built Environments and Mode Choice: Toward a Normative Framework." Transportation Research Part D, 7: 265-284.

Chatterjee, A., and M. M. Venigalla. 2003. "Travel Demand Forecasting for Urban Transportation Planning" (Chapter 7). In M. Kutz, Ed., Handbook of Transportation Engineering. McGraw-Hill Publications.

Chatman, Daniel G. 2008. "Transit-Oriented Development and Household Travel: A Study of California Cities, Final Report." Institute of Transportation Studies School of Public Affairs, University of California, Los Angeles. 
Faghri, Arsalan. 2012. "Advanced Planning Models for Transit-Oriented Developments." Dissertation, George Mason University, May.

Faghri, A., and M. M. Venigalla. 2013. "Measuring Travel Behavior and Transit Trip Generation Characteristics of Transit-Oriented Developments." Transportation Research Record, 2397: 72-79.

Garber, N., and L. Hoel. 2010. Chapter 12, "Forecasting Travel Demand." In Traffic and Highway Engineering, Fourth Edition. West Publishing Company.

Gebeyehu, M., and T. Shin-ei. 2007. "Diagnostic Evaluation of Public Transportation Mode Choice in Addis Ababa." Journal of Public Transportation, 10(4): 27-50.

Hendricks, S. J., P. Winters, F. Wambalaba, S. Barbeau, M. Catala, K. Thomas, E. S. Fleury, J. Flynn, and J. Goodwill. 2005. "Impacts of Transit-Oriented Development on Public Transportation Ridership. Final Report." Center for Urban Transportation Research. University of South Florida.

Holroyd, E. M., and D. A. Scraggs. 1966. "Waiting Time for Buses in Central London." Traffic Engineering and Control, 8: 158-160.

Koppelman, F. S., and C. Bhat. 2006. "A Self Instructing Course in Mode Choice Modeling: Multinomial and Nested Logit Models." Prepared for U.S. Department of Transportation, Federal Transit Administration.

Lancaster, K. 1971. Consumer Demand: A New Approach. New York: Columbia University Press.

Lin, J., and Y. Jen. 2009. "Household Attributes in a Transit-Oriented Development: Evidence from Taipei." Journal of Public Transportation, 12(2): 105-125.

Lund, H. 2006. "Reasons for Living in Transit-Oriented Development and Associated Transit Use." Journal of the American Planning Association, 72 (3): 357-366.

Lund, H., R. Cervero, and R. Wilson. 2010. "Travel Characteristics of Transit-Oriented Development in California." CALTRANS California and FTA.

Messenger, T., and R. Ewing. 1996. "Transit-Oriented Developments in the Sun Belt." Transportation Research Record, 1552: 145-153.

Metro Washington Council of Governments (MWCOG). 2010. “The 2007/2008 TPB Household Travel Survey: Technical Documentation."

Milone, R. 2013. "Validation of the Version 2.3 Travel Demand Model." Memorandum submitted to Transportation Planning Board, Metro Washington DC Council of Governments.

O'Sullivan, S., and J. Morrall. 1996. "Walking Distances to and from Light-Rail Transit Stations." Transportation Research Record 1538: 19-26.

Osuna, E. E., and G. F. Newell. 1972. "Control Strategies for an Idealized Public Transportation System." Transportation Science, 6: 52-72. 
Transit Cooperative Research Program (TCRP) Report 102. 2004. "Transit-Oriented Development in the United States: Experiences, Challenges and Prospects." Transportation Research Board.

Transit Cooperative Research Program (TCRP), Report 95. 2007. "Chapter 17. TransitOriented Development Traveler Response to Transportation System Changes." Transportation Research Board.

\section{About the Authors}

Mohan Venigalla, Ph.D., P.E. (mvenigal@gmu.edu) is an Associate Professor of Civil Engineering with the Sid and Reva Dewberry Department of Civil, Environmental and Infrastructure Engineering at George Mason University in Fairfax, Virginia. His career as a transportation professional has spanned 25 years across consulting, research, and academic institutions. He currently teaches undergraduate and graduate courses in transportation engineering and planning and conducts research in the areas of transportation systems planning, including transit-oriented developments.

Arsalan Faghri, Ph.D., P.E. (Arsalan.Faghri@vdot.virginia.gov) earned a Bachelor of Science degree from York University in Toronto, Canada; a Master of Science degree in Civil Engineering from University of Delaware; and a Ph.D. in Civil Engineering from George Mason University. He is currently a senior transportation engineer with the Virginia Department of Transportation (VDOT). Prior to joining VDOT he was Senior Traffic Engineer at Jacobs Engineering. He teaches graduate level courses in traffic engineering, the Highway Capacity Manual, and traffic network simulation and modeling. His areas of expertise include traffic engineering, land development engineering, and transportation planning and policy. 